\title{
Urban-planning sustainability problems in a city natural framework
}

\author{
Elena Shcherbina ${ }^{1}$, Elena Gorbenkova ${ }^{2 *}$, and Mikhail Slepnev ${ }^{1}$ \\ ${ }^{1}$ Moscow State University of Civil Engineering, Yaroslavskoeshosse, 26, Moscow, 129337, Russia \\ ${ }^{2}$ Belarusian-Russian University, HighwaysDepartment, 212000, 43, Prospect Mira, Mogilev, Belarus
}

\begin{abstract}
The paper contains the research results of the state of Moscow specially protected natural areas (SPNA). The results obtained has allowed to establish the negative factors leading to the SPNAdegradation. The reason is the contradiction between the interest to improve population life quality by using theSPNAas a recreational areas and the interest to preserve valuable landscapes in accordance with the law. It was indicated that recreational load has a significant negative impact to the natural areas. The project experimental results were presented at the example of «Elk Island» National Park. The recreational load control should be by means of urban planning regulation. This is achieved by reducing the population density at the natural area boundaries in preparing the land use and development regulations at a master plan designlevel.A zoning schemeof an area by the recreational load level (subzones) and urban planning regulations for the using of land plots and real estate properties or public improvements should be prepared when developing recreational area planning design at the urban planning level. Complex of these measures will ensure the sustainability of natural city complex.
\end{abstract}

\section{Introduction}

The high rates of urbanization come with the area extension of industrial and residential territories, which are located in a close proximity to natural areas, and expansion in the automobile transport amount. As a result the anthropogenic impacts to the natural complex increase, which is especially evident in the metropolises. These points to the conflict of objectives, which is a real necessity of operating the urban Snares for recreation and legal restrictions for its use. A similar situation was created not only in Moscow region, but also in many other regions of Russia and foreign countries. This causes a need for the development of a new paradigm in the SPNA urban planning management in compliance with the sustainable development concept $[1,2]$.It is worth mentioning that the agriculture development and changes in the rural settlement system lead to the fragmentation and reduction of settlement territories whileSNPAs occupy minor areas. They are all located at a distance from each other and cannot ensure the sustainable development of the natural framework by themselves [3-5].

*Corresponding author: gorbenkowa@yandex.ru 
The idea of natural resource sustainable usage has received a conceptual continuation in the decisions of V SNPAs World Congress (2003, Durban). The basis for a new paradigm in relation to SPNAscreated by the Congress resolution [6,7]. Congress has proved the necessity for changes ofSPNAs management strategy for the greater public good. For the first time Urban SPNAs issue was raised in the international arena within the framework of the Congress. SPNAsimportance for providing urban residents with opportunities for recreation and environmental education along with ecosystem services (environment improving, environment stabilizing, etc.).Urban SPNAsare formed because of urban planning; they have a unified complex of natural and urban planning function processes. From the viewpoint of the systemic approach, SPNAs can be designated as the naturalanthropogenic territorial complexes (NATCs), as noted by A. Kurbatova[8].Such territory allocation is based on a functional uniformity and clear delimitation in the structure of a city master plan and allows using the ecological mapping principles for urban planning of recreational areas and SPNAs[9].

A natural complex perceives an increasing recreational load that is the most significant component of anthropogenic load for the metropolis. The recreational load of natural and green-planted objects causes the negative changes the whole ecosystem units as in a forest biogeocenosis, caused by uncontrolled recreational forest utilization [10,1].

NATC recreational load depends on the closeness to the residential development, the vehicle access, the recreational appeal and public improvements level. The field survey of environmentally significant objects, performed by A. Drozdova et al. shown the high recreational load level at the improved areas of parks and water-conservation zones, while the ravine complex ecosystems include mainly the unfrequented places, even near the settlements, so the natural communities are saved there[1].This indicates the planning concept use efficiency of such recreational spaces as being the natural visitor barriers.

The population concentration in the centres while decreasing it to the outskirts is mainly typical forth world metropolises. Moscow shows the polarity: the population increases with the distance from the centre [11], and high building intensity around the Moscow Ring Road is almost led to the Moscow suburban zones degradation. All of this is detrimental to the natural framework development [12].

\section{Experimental sections}

The 19 natural parksof Moscow regions have the status of specially protected natural areas (SPNA). They are the national park «Elk Island», the natural park «Bits forest», the natural park «Izmailovo Park» and the others. They fall under a significant anthropogenic impact. The field survey data have shown that Moscow SPNAs contain the objects of improved area maintenance; the objects of recreational city functions software and external users' buildings [13].Natural areas are being exposure to negative impact complex because of city living. Figure 1 shows the model of the system «techno-genic source - natural environment» from the viewpoint of the environmental approach. The model treatment was taking as a basis of ourresearch. 


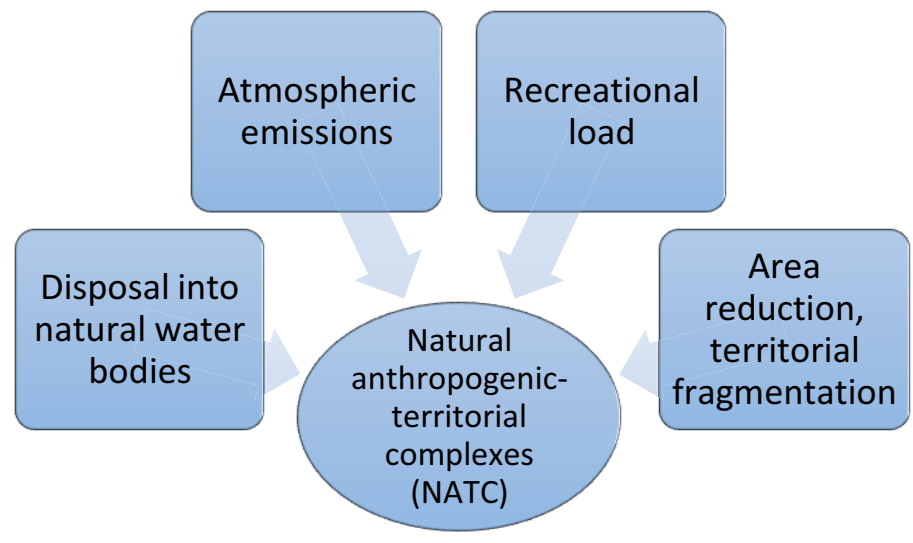

Fig. 1.Model of the system «techno-genic source - natural environment»

The pollution of the surface and underground water sources is caused by industrial waste disposal. This lead to the changes and degradation of aquatic ecosystems, which is the subject of special studies. Solving the problem of discharges and emissions into the environment consists in improving the industry technological cycles and implementing new discharge and emission treatment methods. Program of industry relocation outside the city limits, location of a new creative industry with the minimal environmental pollution - all of this are the urban-planning instruments for a problem solution.

Atmospheric contaminations caused by vehicle influence and industry emissions, which leads to the green planting degradation: trees, bushes and poiums. The solution is in improvement the technological cycles of emission purification, the conversion to more perfect fuels and creation of sanitary-hygienic zones.

The increasing in recreational load, which is perceived by the ecosystem, the territorial fragmentation and area reduction of natural objects lead to a stability reduction of newlyformed NATCs. The inefficient urban planning solutions, which are associated with the city growth dynamics and with its economic potential increase, cause the problems of recreational load increasing and NATCsfragmentation. The territorial complex analysis is the basis for urban-planning decision-making at different territorial planning levels (from the general urban-planning to planning schemes), but the economic estimations remain the defining. The city-planning structure is creating; the permitted types of plots and real estate objects and urban-planning regulations are defined; the structure of population density distribution is forming based on this analysis. Therefore, the specific«boundary conditions» are creating, NATCs find themselves there. Those, the city master plan is developed without an environmental assessment and two levels - urban planning and urban designing -are performed independently, while the second is completely subordinate to the first, what leads to the negative environmental consequences. We propose the decision-making circuit, which provides the coupling of the1st and 2nd preparation levels of urban planning documentation to ensureNATCssustainability (Fig. 2). 


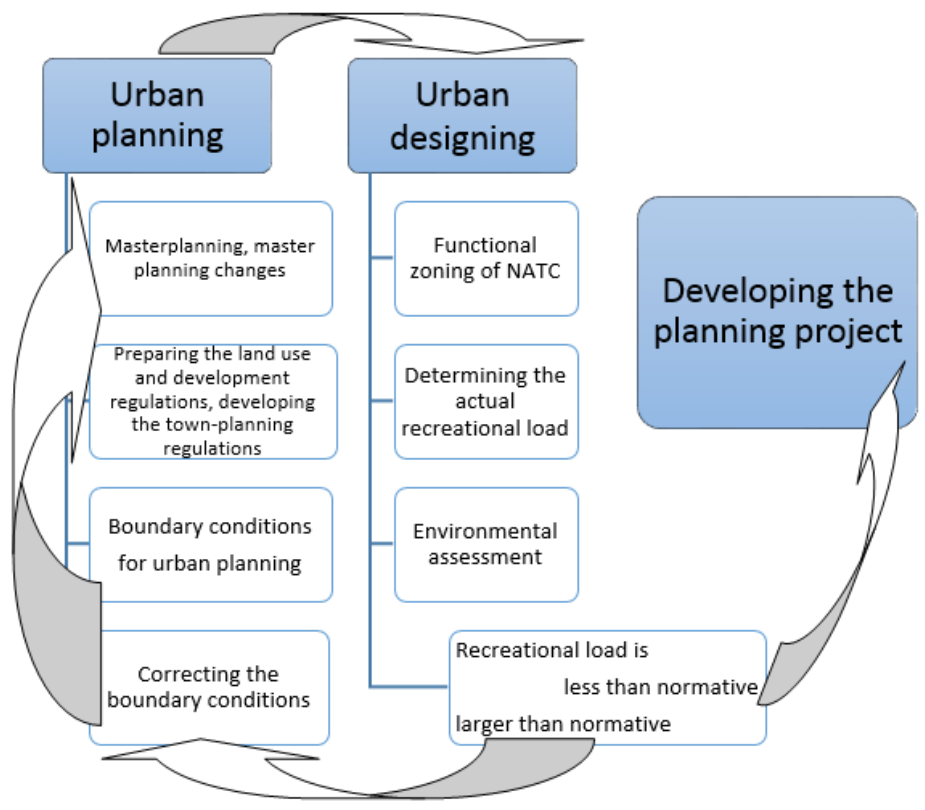

Fig. 2. The sequence of steps to ensure NATCs sustainability

Let us formulate the sequence and the structure of problems. The main problems to be solved at the first level and the sequence of steps are:

1.1. Collecting and analyse the urban planning documentation.

1.2. Delimitating of NAT borders.

1.3. Preparing the land use and development regulations and town-planning regulations for new or redevelopment functional zones within 1,000 meters from the NAT borders.

1.4. Determining the number of NAT potential visitors (recreants).

1.5. NATC areas survey: definition the objects located at bvNATC territory; composing the set of maps required for the area planning designing.

1.6. Developing the eurban-planning regulations for NATC functional areas [14].

The main problems to be solved at the second level and the sequence of steps are:

2.1. Developing the planning concept solutions.

2.2. Functional areas definition according to the anthropogenic impact.

2.3. Determining the actual recreational load within the boundaries of functional zones.

2.4. Estimating the functional zoning solution with the recreational load level. If the recreational load exceeds the rated values, you should consider another functional zoning solution and get back to p. 2.3.

If it is unable to find the solution, you should change the boundary conditions for the 1 'st level (urban planning) and proceed to p. 1.3.

If the recreational load is within the allowable rates, it is possible to start developing the planning scheme (p. 2.5).

2.5. Developing the NATC planning scheme according to the urban planning regulations (p. 1.6).

It is proposing to define four zones for determining the number of NATC potential visitors:

- external vehicle accessibility zone, within the limits of 1500 meters from NATC borders;

- external walking zone within the limits of $500 \mathrm{~m}$ from NATC borders; 
- internal walking accessibility zone of the territory (the most active recreational pressure zone, recreation zone) at NATC $-500 \mathrm{~m}$;

- specially protected zone with the minimal visitor access; the territories for realizing environmental-education and excursion activities are allocated with this zone (within the limits of 50 meters from the attraction points).

\section{Results section}

The project experiment was made in the Moscow part of the national park «Elk Island», which is primarily intended to be a recreation area (2594 ha). The third-party customer territories occupy 399 ha [15]. The potential number of the national park visitors and functional areas, which are constructed within the existing public improvements and landuse management, are presented at Fig. 3.

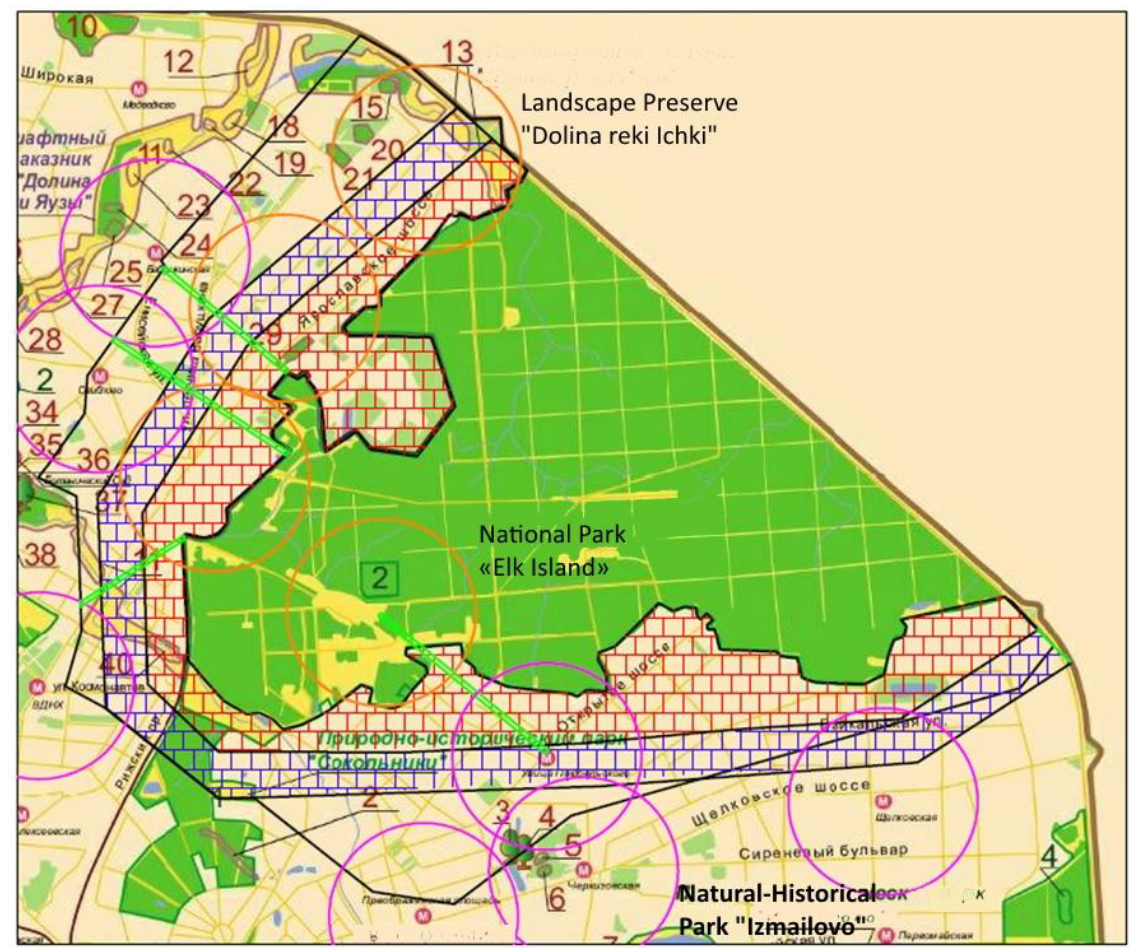

Legend:

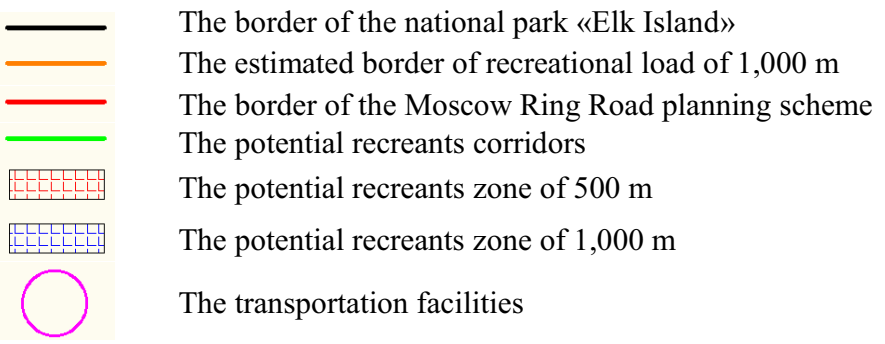

Fig.3.The schematic map for determining the potential number of visitors the territory of National Park «Elk Island». 
The potential visitors 'number is defining by the walking and vehicle accessibility, and now it is equal to 133,000 people, considering purely resident population [15]. Thus, the average recreational load for the Moscow part of the «Elk Island» is 24people/ha. Supposing, that the allowable recreation load for educational tourism zone is 10persons/ha (which corresponds with the forest-park norms), the recreational load for recreation zone is 40 people/ha (resort parks). Such a high recreational load value has a high-level threat for stability of the National Park biocenoses. Therefore it is necessary to detail the recreational load map considering the attraction centers of recreation objects, cultural heritage, that have been identified earlier during the field survey for organizing the recreational activity [16].

The maximum promising recreational load for particular areas is determined from the formula:

$$
R_{k}=\Sigma N_{i j} / \Sigma S_{k j}
$$

where $R_{k}$ - promising recreational load for the $k$-th area;

$N_{i j}-$ therecreants'number of $j$-th zone of recreational accessibility from the side of $i$ th residential formation;

$S_{k j}$ the square of the $k$-th area relating to the $j$-th zone of recreational accessibility.

The obtained values of calculated recreational load should not exceed the normative values for the separated subzones. Such a detailed recreational load map will allow you to formulate the recommendations for organizing an area planning structure. These recommendations will be aimed at improving the environmental state by taking into account its recreational carrying capacity.

\section{Conclusions}

The recreational load causes a significant degradation of the cities ecosystem. Its value is determined by the planning structure of urban areas. This structure defines the population density distribution and vehicle accessibility of recreational objects.

It is necessary to ensure the interrelation of urban planning and designing for a sustainability of natural-anthropogenic systems. At the same time, the urban planning results should not be the boundary conditions for the implementation of the NATC planning project. The urban planning characteristics in general and the residential buildings density in particular are necessary to set taking into account not only the engineering and transport systems, but primarily the environmental evaluation, which allows to regulate the recreational load.

The NATC functional zoning principle allows realizing the efficient areas use in order to preserve the most valued part of ecosystem.

\section{References}

1. E. Drozdova, A. Kornilov, Ju. Belickaja,Geology, geography and global energy,4 (51), 182-190, (2013).

2. E. Sherbina, N. Danilina, D. Vlasov, IJAER,10 (22), 43131-43138 (2015).

3. Elena Shcherbina, Elena Gorbenkova, MATEC, 86, 07002, (2016).

4. P. Davidenko, E. Gorbenkova, City planning, 5 (39), 37-70, (2015).

5. A. Kornilov, A. Petin, Euro-Asian Journal of sustainable energy development policy,1 (1), 45-48, (2008).

6. URL:www.iucn.org/themes/wcpa 
7. URL: http://istina.msu.ru/publications/book/15382350/

8. A. Kurbatova,Landscape-ecological analysis of the formation of urban structures,(2004).

9. E. Shcherbina, M. Slepnev,Ecology of Urban Areas,2, 92-97, (2016).

10. M. Serikov,Forestry Engineering Journal, 2, 75-83, (2013).

11. N. Krasnoshchekova, City planning, 4, 67-76, (2014).

12. Alain Bertaud, Stephen Malpezzi, The Spatial Distribution of Population in 48 World Cities: Implications for Economies in Transition, (2003).

13. Lju Jujhan, M. Slepnev,Proc. of the International Scientific and Practical Conference Trends in the development of science and education, 2, 35-37, (2016).

14. M. Slepnev, E. Tcherbina,Ecology of Urban Areas,3, 68-73, (2015).

15. URL:https://mnr.gov.ru/upload/iblock/ba6/losinij\%20ostrov\%20prikaz.doc

16. E. Shcherbina, M. Slepnev, Science Review,6, 240-244, (2016). 